\title{
ВАРИАТИВНОСТЬ СТРУКТУР СИНТАКСИЧЕСКОГО АНАЛИТИЗМА В РУССКОМ ЯЗЫКЕ
}

\section{THE VARIATY OF SYNTACTIC ANALYTISM STRUCTURES IN RUSSIAN LANGUAGE \\ M. Efremova}

Summary: The article is devoted to the usage of the variation of syntactic analytism structures in the Russian language. This variaty is consist in the choice of the type of intonation construction and its usage in neutral or emotionally-colored sentences. In spoken speech, the interaction of intonation with vocabulary, syntax, and context is important. Thus, the variaty of the structures of syntactic analyticism in spoken speech will be only in sentences with the same lexical and grammatical composition, but different intonation and context. Meanwhile the type of intonation construction or the location of the center of intonation construction could be changed.

Keywords: analytical structures, interaction, oppositions, variety.
И зучение аналитизма имеет длительную историю, которая началась еще в середине XIX века в связи с тенденцией языков либо к аналитическим, либо к синтетическим структурам. Синтетическими принято считать те структуры, которые имеют указание на определенный коммуникативный тип высказывания. Например, Когда человек начинает рассуждать о лингвистических проблемах, он должен руководствоваться и опираться на ту информацию, которая уже была доказана известными учеными-филологами. Как правило, это повествовательные предложения, поскольку они должны быть достаточно информативны для передачи полного объема информации. Описание таких структур в современном русском языке необходимо для правильного обучения русского языка как иностранного, а также понимания иностранцами структур синтаксического аналитизма, которые широко используются в разговорной речи. Поэтому задачей данного исследования было описать структуры синтаксического аналитизма, а также показать их вариативность, которая учитывает взаимодействие лексики, синтаксиса, интонации и контекста.

В русском языке в девяностых годах XX века В.Г. Гак выделил лексический, морфологический и синтаксический аналитизм. В статье в Лингвистическом энциклопедическом словаре он дает следующее определение аналитизма: это «типологическое свойство языка, которое проявляется «в раздельном выражении основного (лексического) и дополнительного (грамматического, словообразовательного) значения слова» [Гак 1990: 31].

\author{
Ефремова Мария Юрьевна \\ старший преподаватель, Московский государственный \\ университет имени М.В. Ломоносова \\ efremovamy@mail.ru
}

Аннотация: В статье исследуется вариативность структур синтаксического аналитизма в русском языке. Эта вариативность проявляется в выборе типа ИК и его употребления в нейтральных или эмоционально-окрашенных высказываниях. В звучащей речи важным является взаимодействие интонации с лексикой, синтаксисом и контекстом. В результате определено, что вариативность структур синтаксического аналитизма в звучащей речи будет только в предложениях с одинаковым лексико-грамматическим составом, но разными интонацией и контекстом. При этом может меняться тип ИК или место центра ИК.

Ключевые слова: аналитическая структура, взаимодействие, оппозиция, вариативность.

Данное В.Г. Гаком определение, в котором он разделяет выражения лексического и грамматического значений, характерно для морфологического аналитизма, так как ориентировано на германские и романские языки. Однако ошибочно считать грамматическое выражение второстепенным. При этом он не учитывает интонационное оформление предложений, которое не существует в отрыве от звучащей речи и которое может служить важным различительным признаком.

М.В. Панов дал другое определение аналитизма, как «Выражения грамматического значения слова вне его пределов» [Панов 1968: т. 1, 1-25], однако здесь слово также рассматривается без учета интонации. Значение слова в звучащей речи определяется не только его формальными показателями, но также зависит и от контекста, и от интонации. Можно дать следующее определение синтаксического аналитизма, как такой структуры, которая проявляется в определенных лексико-грамматических предложениях при взаимодействии с интонацией, определенным контекстом, что необходимо для выражения коммуникативной цели говорящего. Такие структуры могут иметь разное значение при изменении места центра интонационной конструкции (ИК), что говорит об их вариативности, которая может проявляться на фонетическом, морфологическом и грамматическом уровнях. Поэтому можно говорить, что при одном и том же лексическограмматическом содержании высказывания благодаря интонации меняется значение этого высказывания. 
Об этом писала Е.А. Брызгунова в Русской грамматике (1980): «Соотношение синтаксических, лексических и интонационных средств высказывания может быть различным, и этим определяются различительные возможности интонации» [АГ-80: т.2, § 1900]. Если грамматическое строение и лексический состав высказывания достаточны для выражения однозначной информации, такие структуры называют синтетическими: И высокий же он! Данное высказывание может быть произнесено с разными типами ИК и местом центра ИК, но это будут эмоционально-стилистические реализации ИК. Если лексико-грамматический состав высказывания является аналитичным, возрастают смыслоразличительные возможности интонации. В качестве примера можно привести различие ИК-1 и ИК-3, когда изменение типа ИК выражает вопрос и сообщение, а также ИК-2 и ИК-5, выражающих вопрос и оценку.

- В автобусе контролё ${ }^{3}$ ? (вопрос)

- В автобусе контролёр1 р. (сообщение)

- Какогй сегодня день? (вопрос)

- Како й сегодня де ${ }^{5}$ нь! (оценка)

Структуры синтаксического аналитизма обладают вариативностью: способностью при одном и том же лексико-грамматическом составе и интонации менять оттенки значения высказывания. Например,

- О чег м ты думаешь? Расскажи. Ситуация не простая. (вопрос)

- О чем ты ду² маешь? У тебя через неделю экзамен. (вопрос с оттенком недовольства)

Способность данных высказываний к вариативности зависит от структуры предложения, которая всегда указывает на определенный тип ИК. Интонация не определяет оттенки значения высказывания, но позволяет образовывать многочисленные ряды в зависимости или от эмоционального состояния говорящего, или от цели высказывания.

- Очег м ты думаешь? Расскажи. (вопрос)

- О че этим головуломал. (вопрос с оттенком недоумения)

Понятие «вариативность» следует отличать от понятия «синонимия» или, в данном аспекте, «интонационная синонимия», которая выражает различные оттенки значений с помощью типов ИК. Таким образом можно дать следующее определение интонационной синонимии употребление различных типов ИК при выражении одного и того же значения с различными эмоциональностилистическими оттенками. Например,

- Холодно. Да, я знаю. (сообщение)

- Холодно. Я надену пальто'. (указательность)

- Хоблодно. Да', / уже осень. (оценка, положительное или отрицательное содержание которой становится ясно из контекста)

- Холодно. Ну, что делать? Зима'! (оценка)
Представляется необходимым уточнить применяемые в статье термины и понятия. Основой теории служит разработанная Е.А. Брызгуновой система типов интонационных конструкций (ИК), которые раскрывают свое значение во взаимодействии с лексикой, грамматикой и контекстом. «Смыслоразличительные возможности интонации наиболее ярко проявляются при сравнении высказываний с одинаковым синтаксическим строением и лексическим составом или высказываний с разным синтаксическим строением, но одинаковым звуковым составом словоформ» [АГ-80: т.1, § 151]. Вариативность структур синтаксического аналитизма в рамках теории ИК заключается в определении интонационных средств языка при выражении как основного значения высказывания, так и его эмоционально-стилистических оттенков. Один и тот же тип ИК может использоваться для выражения нейтральных и эмоционально-окрашенных значений, поэтому вариативность значений зависит от того, какой тип ИК (нейтральный или эмоциональный) выбрал говорящий. Например, в сочетаниях слова так с глаголом возможно употребление только ИК-2.

- Так подожди²! Так помоги (же)! Так посмотри'!

При синтагматическом членении возможна реализация оттенков.

- $T^{2} \kappa, /$ посмотри²! (приказ, призыв к действию) Центр ИК-2 на слове так вносит в предложение эмоциональную окрашенность.

- $\quad$ - ле $e^{4} m$ сколько же будет?

Вопросительное предложение характеризуется наличием частицы «а», используемой для усиления выразительности, усилительной частицы же, а также порядком слов. Изменение типа ИК, места центра ИК, синтагматического членения и порядка слов могут менять значение высказывания. Подобная вариативность конструкций позволяет шире показать возможности интонации в рамках одного высказывания. Слово, на котором будет место центра ИК, выделено по смыслу.

Приведем примеры интонационной синонимии.

- Мы должны выехать рано утром во что б бы то ни ста丿)

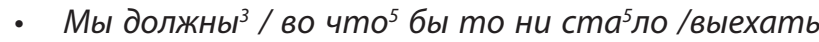
рано утром!

- Мы должны / во что бы то ни ста ло /выехать рано у тром.

- Мы должны во что бы то ни ста²ло /выехать рано $y^{1}$ тром.

- Мы должны / во что бы то ни ста ло /выехать рано у'тром.

Примеры интонационной синонимии можно продолжить, изменяя синтагматическое членение, типы ИК, а также, в отдельных ситуациях, и место центра.

Приведем пример структуры синтаксического ана- 
литизма.

- Вызнаете название моей звезды?

Данное предложение можно представить с разным

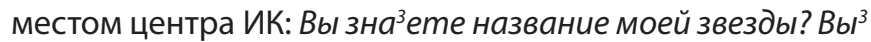
знаете название моей звезды? Вы знаете название моей звездыз ? Вы знаете название мое ${ }^{3}$ зв зезды? В этих предложениях будут работать ассоциативно-тематические связи и связи взаимоисключающего противопоставления: знаете - не знаете; вы - не вы: он, она, они; звезды - не звезды: планеты, кометы; моей - не моей: его, ее, их.

Реализация других интонационных конструкций возможна при изменении порядка слов и синтагматического членения. Можно представить оппозицию коммуникативного значения предложения с помощью ИК-1 и ИК-3, выражающих повествовательный или вопросительный тип высказывания.

- - Название моей звезды $1^{2}$ / вы зна

- Название моей звездыз / вы зна ете.

- - Название мое 2 й звезды / вы зна ете?

- Название мое й звезды / вы зна'ете.

Большим разнообразием обладают предложения с местоименными словами и частицами. В книге «Современный русский язык» под ред. В.А. Белошапковой в главе «Интонация и синтаксис» выделен класс полифункциональных слов, которые могут функционировать как знаменательные и служебные (где, куда, сколько так и др.) или как служебные с разными сочетаниями (вот, вот бы, ну и др.). В структурах синтаксического аналитизма интонация раскрывает потенциальные возможности полифункционального слова, т.е. такого слова, которое имеет потенциальную возможность реализовываться в составе высказываний с помощью интонации. Однако синонимия в таких конструкциях возможна в меньшей степени.

- Лучше занимайся! Иначе в университет не поступишь. (лучше - компаратив)

- Лучше занима йся! Квартиру я буду сам уберу! (лучше - частица в функции, выражающей компонент значения предпочтения).

В следующем примере аналитичный состав высказывания способен образовывать оппозицию, благодаря тому что существительное книг может включаться в оценочные отношения. Это слово несет в себе сему предметности и не имеет указателей на определенный тип предложения. ИК-5 употребляется в оценочных предложениях и передает большую степень выраженности признака, действия, состояния.

- Ско²лько книг он взял в библиотеке? (вопрос)

- Ско лько кни г он взял в библиотеке! И" не сосчи$m a^{5} m b$ ! (оценка)

Слово сколько в русском языке может быть наречием, союзом и частицей. В качестве частицы оно может сочетаться с местоимениями.

- Сколько емулет? (вопрос)

- Сколько емуле ${ }^{3} m$ ? Уже тридиать. (повторение вопроса при ответе)

- Сколько ему ле $e^{2} m$ ! А он всё глупостями занимается. (негативная оценка)

- Ско4лько ему лет? Быть не может. Я думала, он старше. (удивление)

При сохранении лексико-грамматического состава происходит изменение типа ИК, что влечет за собой изменение смысла высказывания. Кроме этого, полифункциональные слова в подобных конструкциях могут образовывать оппозиции при помощи взаимодействия интонации и контекста.

Другое полифункциональное слово так может выступать и как наречие (5-11), и как частица (1-4). Это реализуется с различными типами ИК.

1. $Т a^{2}$ к вот. Уроки прогуливать. (недовольство)

2. Так во ${ }^{2}$... На че ${ }^{2}$ м я остановился? Ебду я, / а он мне навстре $e^{2}$ у. (припоминание)

3. Так $80^{2} m$. Пра²вильно написал. (одобрение)

4. Так во $0^{2}$ о чем ты хотел со мной поговорить! Я $m a^{5}$ к и зна $5 а$ ! (преодоление затруднения при ответе на вопрос)

5. Так он и уше 2 ?! Не может бы $\mathbf{l}^{5}$ mь. (недоумение)

6. Так он уше л? Наконе $e^{2}$ действия)

7. Так он уше 2 л. Даже не попроща루 вшись. (сожаление, обида)

8. Так он и ушегл. Со сканда²лом. Не сказав ни сло ва. (констатация отрицательного факта)

9. Так он (u) ушебл. Не узнав пра'вды. (незавершенность действия)

10. Так он и уше $2 / 7$ л. Жди ${ }^{2}$ К Ка² жее. Оста ${ }^{2}$ лся конечно. (= не ушел)

11. - Все забрал из дома?

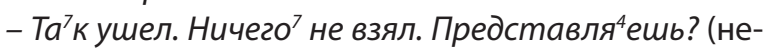
соответствие ожидаемому)

Изменение типа ИК и места центра ИК порождает вариативность структур синтаксического аналитизма.

Как уже было сказано выше, В.Г. Гак разделяет лексическое и грамматическое значения, однако важны оба значения, поскольку лексико-грамматический состав высказывания уже обладает семантикой. Например, предложение Ему холодно заключает в себе значение «субъект и его состояние». Такой лексико-грамматический состав достаточен, чтобы образовать вопрос без вопросительного слова: Ему холодно? - Ему хо лодно. Если лексико-грамматический состав предложения может образовывать оппозиции, он является аналитичным. При взаимодействии его потенциальных возможностей 
с помощью разных интонационных средств и контекста могут выражаться разные значения.

Как было сказано выше, структуры синтаксического аналитизма могут образовывать оппозиции повествовательных и вопросительных предложений. Ремой в обоих предложениях будет интонационно-выделенное слово, которое может выражать связи взаимоисключающего противопоставления. Синтагматическое членение помогает усилить смысловую важность той или иной части предложения. Например,

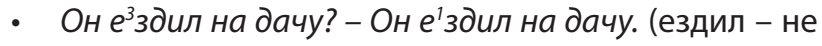
ездил)

- Он купи з билет на самолет? - Он купи л билет на самолет. (купил - не купил)

- Преподаватели зна ют, / что заседание перенесли ${ }^{2}$ ? - Преподаватели зна ют, что заседание перенесли'. (знают - не знают)

Существуют также структуры синтаксического аналитизма, в которых интонационно выделенное слово способно образовывать ассоциативно-тематические ряды.

- Пушкин родился в эำом доме? - Пушкин родился в $э^{1}$ том доме. (в этом - не в этом; в этом - в предыдущем, в следующем)

- Президез нт сегодня выступит с докладом? - Президе ${ }^{1} н$ сегодня выступит с докладом. (президент - не президент; президент - премьер-министр, министр)

Особая роль в структурах синтаксического аналитизма принадлежит контексту, который помогает выявить коммуникативное значение предложения, выражающееся в форме коммуникативного типа предложения и его актуального членения.

В структурах синтаксического аналитизма, т. е. в тех структурах, в которых возможны оппозиции, контекст помогает раскрыть, например, содержание оценки, переданной средствами интонации. Например,

- Кака ${ }^{5}$ я маши ${ }^{5}$ на! Новый ку ${ }^{3}$ зов, сало ${ }^{3}$, мото ${ }^{2}$...

- Кака я маши ${ }^{5}$ на! Вся проржаве ла, е2 здить нельзя.

Положительное или отрицательное содержание оценки содержится в последующем контексте. Слово машина в своей семантике имеет сему предметности, которая в свою очередь позволяет включаться в оценочные отношения.

Также контекст может выполнять функцию различительного признака при выражении обоснования и вопроса. Например,

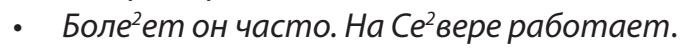

Предложение может быть передано синтетическим способом:
- Боле ет он часто. Дело в том, что он на $\mathrm{Ce}^{2}$ вере paбomaem.

Значение обоснования может быть выражено в реплике-реакции.

- - Боле ет он часто.

- На Ce $e^{2}$ вере работает.

В реплике-стимуле, выраженном вопросом, предыдущий контекст с обоснованием не требуется.

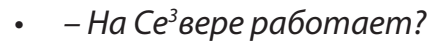

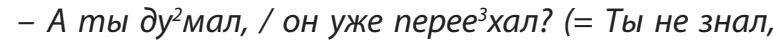
что он уже переехал?)

Существуют предложения, различающиеся наличием или отсутствием частицы не. Такие предложения с одинаковым лексико-грамматическим составом и интонацией могут иметь разные значения.

- - - Тызна ешь, / он не устрог2 ился на новую работу!

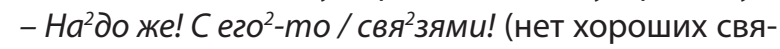
зей для устройства на работу)

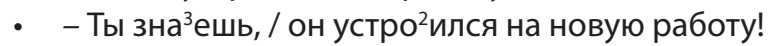

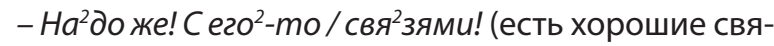
зи для устройства на работу)

В первом диалоге собеседник мало осведомлен о ситуации, тогда как во втором - знает ситуацию и обосновывает свое мнение. Вторые реплики диалогов одинаковы, но имеют разные значения, которые связаны с репликами-стимулами. Такие предложения являются структурами синтаксического аналитизма.

Данные предложения можно выразить синтетическим способом.

- - - Ты зна еши, / он не устрог ился на новую работу!

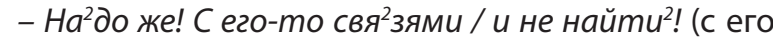
связями не мог найти работу)

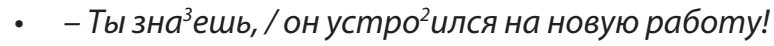

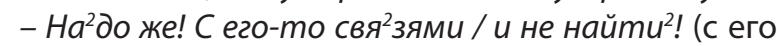
связями он мог найти работу)

В русском языке подобные диалоги, когда происходит смешение синтетических и аналитических структур, более распространены. Высказывания, начинающиеся с полифункционального служебного слова «а» с помощью разных интонационных конструкций могут менять свое значение.

- - В прошлом году⿰氵 / дом был постро ен.

- Азаселе ${ }^{3} \boldsymbol{H}$ ?

- Eще не $\mathrm{m}$.

- - Дом был построен в прошлом году.

- Азаселе ${ }^{4} H$ ?

- Только в э томом.

В первом диалоге частицу «а» можно опустить: $A$ заселе ${ }^{3}$ ? - Заселе $e^{3}$ ? Во втором «а» является сопостави- 
тельным союзом, связывающим смысловые компоненты реплик, при этом неизвестным является время события: освящен, не освящен.

В некоторых сложноподчиненных предложениях с препозицией главной части, в которой выражена синтаксическая и семантическая завершенность, также может проявляться принцип синтаксического аналитизма. Синтаксическая и семантическая завершенность помогают усиливать смысловую самостоятельность главной части.

- В Сретенском монастыре освятили хра м, / который был построен на народные де $e^{1}$ ньги.

Интонация может усилить подчинительную часть высказывания:

- В Сретенском монастыре освятили хра м, /который был построен на наро 2 дные деньги.

Главная часть высказывания строится по принципу синтаксического аналитизма, когда лексико-грамматический и звуковой состав не изменяются, но интонация меняет смысловой компонент. Однако с помощью дополнительного компонента - местоименного слова mom - данное предложение может быть построено по принципу синтетизма.

- В Сретенском монастыре освятили тоㅜㅡ храм, / который был построен на народные де ньги.

В русском языке в разговорной речи преобладают структуры синтаксического аналитизма, которые конкретизируют свое значение в составе высказывания при взаимодействии лексики, синтаксиса, интонации и их связей в контексте. Лексико-грамматическое оформление таких структур позволяет образовывать различные коммуникативные типы высказываний (например, вопрос, сообщение, оценка) с помощью интонации. Вариативность структур синтаксического аналитизма возможна благодаря оформлению высказываний различными типами ИК, как нейтральными, так и эмоционально-окрашенными.

Обучение иностранцев структурам синтаксического аналитизма дает лучшее понимание русской разговорной речи. На данном материале рассматривается все многообразие интонации, которое необходимо для использования смыслоразличительных особенностей русского языка среди иностранцев.

ЛИТЕРАТУРА

1. Брызгунова Е.А. Интонация и синтаксис // Современный русский язык / под ред. В.А. Белошапковой. 3-е изд., испр. и доп. М., 1999. С. 869-902.

2. Брызгунова Е.А. ст. Синтаксический аналитизм в русском языке // Лингвистика от Востока до Запада. В честь 70-летия В.Б. Касевича: Сборник статей / под ред. Л.А. Вербицкой. СПб.: Филологический факультет СПбГУ, 2011. С. 311-320.

3. Брызгунова Е.А. ст. Фонологический метод при изучении морфологического и синтаксического аналитизма в русском языке // Язык и речевая деятельность. СПб.: Филологический факультет СПбГУ, 2011. Том 10-11. Сс. 45-58.

4. Виноградов В.В. Русский язык: Грамматическое учение о слове. М., 1947.

5. Гак В.Г. Аналитизм // Большой энциклопедический словарь. Языкознание. Под ред. В.Н. Ярцевой. 2-ое изд. Лингвистического энциклопедического словаря. М.: Научное изд-во «Большая Российская энциклопедия», 2000. С. 31.

6. Гак В.Г. Синтетизм // Большой энциклопедический словарь. Языкознание. Под ред. В.Н. Ярцевой. 2-ое изд. Лингвистического энциклопедического словаря. М.: Научное изд-во «Большая Российская энциклопедия», 2000. С. 451.

7. Гловинская М.Я. Просто оговорки или тенденция к аналитизму? // Язык: переменчивость и постоянство. М.: Ин-т русского языка имени В.В. Виноградова PAH, 1998. C. 304-316.

8. Панов М.В. Русский язык и советское общество: Социолингвистическое исследование. Коллективная монография / под ред. М. В. Панова. Т. I-IV. М., 1968.

9. Русская грамматика в 2-х тт. М.: Наука, 1980.

(c) Ефремова Мария Юрьевна (efremovamy@mail.ru).

Журнал «Современная наука: актуальные проблемы теории и практики» 